\title{
RICH ENVIRONMENTS FOR ACTIVE OPEN DISTANCE LEARNING: LOOKS GOOD IN THEORY BUT IS IT REALLY WHAT LEARNERS WANT?
}

\section{R. Queiros*}

Department of Transport Economics, Logistics and Tourism e-mail: queirdr@unisa.ac.za

\section{R. de Villiers*}

School of Computing, Unisa

e-mail: ruth.devilliers1@gmail.com/dvillmr1@unisa.ac.za

\section{C. van Zyl*}

Department of Transport Economics, Logistics and Tourism e-mail:vzylc@unisa.ac.za

\section{N. Conradie*}

Department of Transport Economics, Logistics and Tourism e-mail: conran@unisa.ac.za

\section{L. van Zyl*}

Department of Industrial and Organisational Psychology e-mail: vzylle@unisa.ac.za

*University of South Africa Pretoria, South Africa

\section{ABSTRACT}

In the open distance learning environment, efforts are made to engage students and provide rich environments for active learning (REALs). This article describes exploratory research undertaken on a fourth-year Tourism Management module.

\section{UNISA $\cong$}


The research investigated two different study guides for different years - 2012 students using an innovative guide with learner engagement tools designed in line with current learning theory, to achieve a REAL; and 2011 learners using a traditional study guide with far fewer engagement tools. The two consecutive cohorts completed a quantitative survey designed from theory on learner engagement, motivation and interactivity. The survey investigated learners' experiences of the implementation of four constructs, namely course design; engagement; learning activities; and the integrated construct of relevance, application, bonding and ownership. Data analysis was conducted using descriptive statistics, non-parametric correlations and cross-tabulations. Results suggest that this REAL does aid learning but not to the extent anticipated, and that it may be too rich. In light of the greater debate regarding the design of ODL material to maximise learning, recommendations are made to discerningly regulate the richness and depth of learning material, avoid overload of isolated learners, and gradually introduce REALs.

Keywords: open distance learning (ODL), rich environment for active learning (REAL), constructivism, engagement, motivation, interactivity, learner activities, course design, relevance, application, bonding, ownership

\section{INTRODUCTION}

In the open distance learning (ODL) environment of the University of South Africa (Unisa), efforts are made to counteract isolation by engaging distance learners. One way of doing this is to employ approaches and activities that enhance student ${ }^{1}$ engagement, motivation and interactivity in order to provide rich environments for active learning (REALs) (Grabinger and Dunlap 1995). This study investigates the impact of innovative study material, which integrated authentic activities into the new study guide for a fourth-year module in Tourism Management (Advanced Tourism Development and Ecotourism) offered within the College of Economic and Management Sciences (CEMS) at Unisa. The new material aims to enrich and support learners by providing a REAL that, although more challenging, should motivate students, encourage cognitive engagement and prepare them for the workplace. To ascertain students' perceptions of the material and activities, quantitative survey research was undertaken among two successive cohorts. The first study was conducted in 2011 among the final cohort to use the traditional study guide (to investigate attitudes to the familiar approach), while the 2012 study probed attitudes of the first cohort to use the more engaging study guide.

This work is situated in an ODL institution in South Africa where the printed study guide is being replaced by online learning in a blended learning context. The former study guide in this module offered limited learner engagement opportunities, an approach which characterised traditional study material in this institution. The 2012 study guide, however, included a REAL ethos. This study guide was initially developed for online delivery and interaction, but due to scheduling changes it was produced in print. 
Constructivist learning theory and the key constructs of course design, engagement, learner activities and relevance were gleaned from literature. They were applied, firstly, in the development of learning activities for the new study guide and, secondly, were converted to evaluation criteria phrased as questionnaire items and administered to learners online to ascertain their experiences and opinions on their study material. To respond to the question in the title, this research investigates learners' perceptions of the implementation of the four key constructs in the study material of 2011 and 2012 respectively. This article describes efforts to map and record the reflective research on designing and evaluating new study material and comparing it to former material. Furthermore it makes a new contribution in that it describes the first ventures in this module to increase learner engagement.

Section 2 provides the background to this work, while section 3 reviews related literature. The research question and methodology are presented in section 4. Section 5 reports and discusses the results, some of which support the direction which ODL is taking in the Unisa context, while other findings are unexpected and raise questions. Section 6 concludes the article and provides recommendations.

\section{BACKGROUND AND THE NEW STUDY MATERIAL}

New approaches to teaching and learning change the role of educators in ODL from being mere providers of knowledge (teachers) towards serving more as facilitators offering multiple perspectives on learning content, thus encouraging students to engage deeply and independently. Not only must the human stakeholders undergo a paradigm shift but the tools and resources must also undergo a concomitant change to support the new ethos.

The research is based on a comparison between the two study guides and their impact. In the traditional context up until 2011, the module's study guide only included icons to denote learning objectives, self-assessment questions, definitions and references. Most chapters contained a case study. The material was interesting but was primarily used by learners in a passive way. An example of two pages from this study guide is shown in figure 2.1.

To meet the challenge of new designs for course material and to encourage active learning, a variety of activities and resources were incorporated in the new 2012 study guide, which was developed in close collaboration with Unisa's Directorate of Curriculum and Learning Development (DCLD). It contains current material and far more examples and case studies to apply theory. Furthermore, it is written in a firstperson informal style, allowing students to 'hear' the educator's voice via the material, for example, 'we have investigated ...', 'let's look at ...' etc. It goes beyond icons to denote objectives and definitions, and in line with the title uses what the authors term 'learner-engagement tools' to offer a REAL with constructivist learning material, as far as is possible in an ODL environment. There is also extensive use of photographs, 
figures and logos. Every page spread was explicitly designed to be eye-catching and interesting. Each learning unit commences by presenting the learning outcomes. The study guide is innovative in its context of use due to learner-engagement tools that facilitate positive learner engagement, motivation and learner-centred interactivity. The tools are presented by thematic headers such as 'Reflection', 'News Flash!' and 'Watch This!' (see figure 1). Furthermore, a DVD with video clips accompanied the study material. Figure 2.2 presents excerpts from the new study guide to illustrate some of the engagement tools. The material was initially designed for online delivery, but due to a change in schedule it will go online in 2015. Other aspects of the learning experience (such as student support and involvement of the educator) and the assessment (two essay-type assignments and a written exam) remained constant over the two years.

\begin{tabular}{|l|l|}
\hline Rescription \\
\hline Refinitions. This icon draws your attention to certain keywords or concepts that need to be defined.
\end{tabular}

Figure 1: Learner engagement tools used in 2012 study guide 


\begin{tabular}{|c|}
\hline 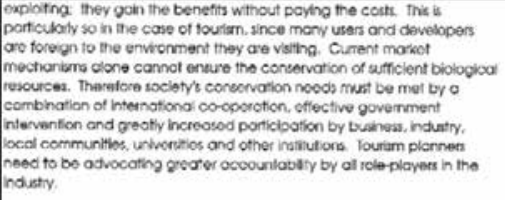 \\
\hline 12.B DUESTIONS FOR SELF-ASSESSMENT \\
\hline 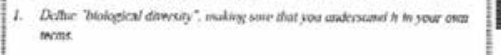 \\
\hline 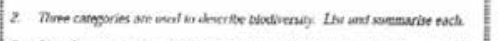 \\
\hline 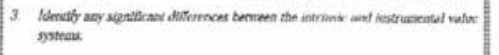 \\
\hline 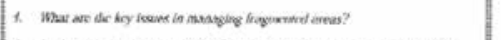 \\
\hline 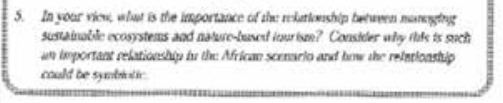 \\
\hline 12.9 RECOMMENDED READING \\
\hline  \\
\hline 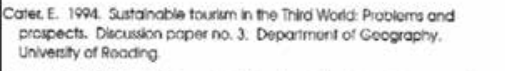 \\
\hline 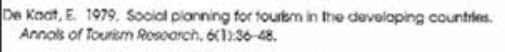 \\
\hline $\begin{array}{l}\text { Jiabenberg. L. Crecmons. C. \& Mossm. PJ. 1995. A new po } \\
\text { The economic contribution of key conservation areas ins }\end{array}$ \\
\hline
\end{tabular}

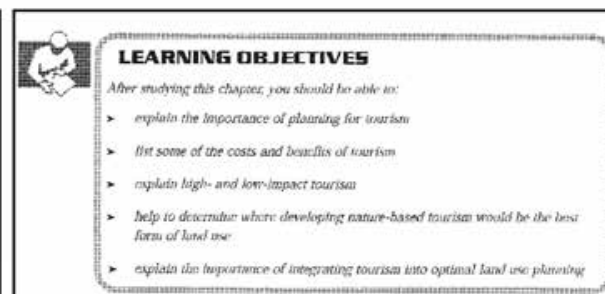

\subsection{INTRODUCTION}

Noture-based tourism in dovoloping countilios has had a stormy history. South Atrica has been no exception. with rura: communtes orien having been excluded not only from louriam pianring but also from the enviroment in which they tive, in the suoposec hiterests of tourim. Hence their irterests ond those of tourim nove been percelved cs mufually exclualve.

As most naturo-basod tourism in Southem Africa occurs in oreas where there are rura comminities. nctute-bxaed tourism shoulc alow "or some hevel of community involvement. This wovid be in the interests of long. term sustoincolity.

Toursm plenning for this sector of tourism has been deficient moinly becouse nature-basod tourism has onily recentiy been developed to sevve the growing maket. The emphosis has cleary been on product dovelopment of the miciolevel rether than on the larger picture, and tounism has not alwoys been thoroughty integrated into reglono dovelopment planing. Ony now, theretore, have the environmental and socid problems begun to ernerge

Plonners ond managess now need to ceve op mochanims and concepts for manoging the growth of ngture-bosed toursm more sustanably. However, Ssuth Africa lacks protensional tourism planners to co-orcinate and integrote tourism into overal land use planning

Figure 2.1: Excerpts from 2011 study guide showing the more traditional approach
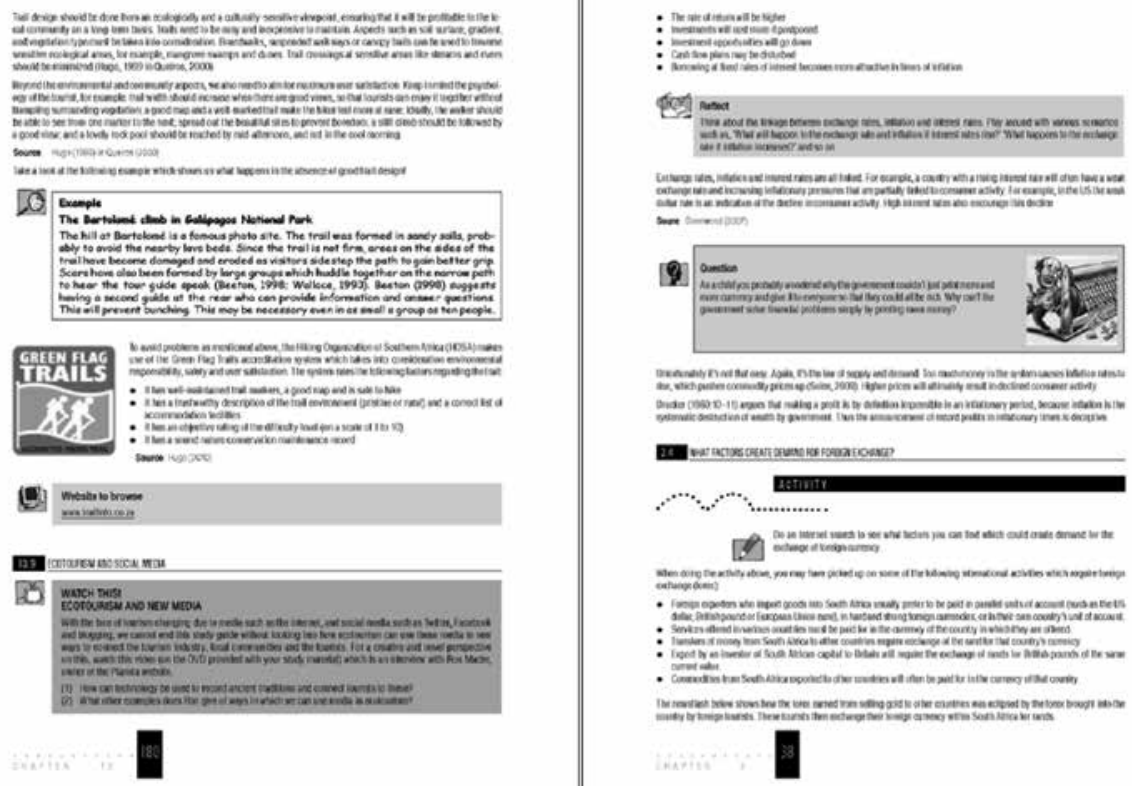

Figure 2.2: Excerpts from 2012 study guide showing implementation of learner engagement tools 


\section{LITERATURE REVIEW}

The concepts discussed in this section influenced the design of the new study material and were also directly applied to generate the evaluation criteria. The underlying learning theory was constructivism. According to the constructivist paradigm, reality for each person is their personal interpretation of what they perceive. Learning is thus a process whereby learners actively construct their own knowledge, with the educator serving as a facilitator. Educational environments that support knowledge construction should emphasise learning rather than teaching; active engagement rather than passive transmission; guided discovery; collaborative activities; negotiation of goals; learner reflection; ownership of learning and activities; and authentic tasks that are personally relevant (Alessi and Trollip 2001; Baniulus, Kersiene, Petreikiene and Slotkiene 2010; Dobrovolny 2006). The aim in this research was to implement constructivist approaches in a situation where printed material is supplemented by activities undertaken by distance learners working in isolation. Such engagement is an antidote to declining academic motivation and achievement (Fredricks, Blumenfeld and Paris 2004). Active engagement with either concepts or agents is often labelled as 'interaction' (Rhode 2009) and can be a key determinant of student success (Ambe-Uva 2006).

Taylor and Parsons (2011) note that efforts to improve student engagement initially focused on helping disengaged students to learn but now emphasise ventures aimed at enhancing learning amongst all students. This shift aims at strengthening students' abilities to facilitate their own learning and embraces the concepts of evolving and flexible education. It advocates changes in curricula, pedagogy and assessment strategies to support contemporary learners (Hsi and Soloway 1998; Willms 2003). 'Net-geners' or 'Millennials' (born mainly between 1980 and 1994) need self-directed learning opportunities and interactive environments using a variety of resources to create personally meaningful learning experiences (Glenn 2000, 2). Learning material should hold attention and encourage focus (Carlson 2005; Hsi and Soloway 1998). Grabinger and Dunlap (1995) encourage rich environments for active learning (REALs) where activities are consistent with the constructivist paradigm, tap into authentic, real-world information-rich contexts, and encourage learners to take responsibility and initiative.

In this research into pertinent theory on learner engagement, interactivity and motivation, four key constructs emerged: (1) course design, (2) engagement, (3) learning activities and (4) relevance, application, bonding and ownership. These constructs and their sub-constructs form the underlying theoretical foundation of this research and were used to investigate learning via the two study guides. Questionnaire items were developed to investigate students' opinions and experiences of the implementation of these constructs in their study material. 


\section{Course design}

Course design should be coherent and cohesive, facilitating motivation, meaningful learning, satisfaction and performance (Moley, Bandré and George 2011; Paechter and Maier 2010). Moley et al. (2011) state that if instructors want students to read and understand a text, think critically and reflect on their thoughts, the type of material should be carefully considered. Features that can enhance learning in printed material are content (age-appropriate and familiar), illustrations, density of document, language structure (flow and repetition), judgement (readers' ability to understand text) and format (font, spacing and layout).

The modality effect forms part of course design and refers to supplementing text with the spoken word, while the cueing effect relates to incorporating visual cues and graphics into text. These can result in improved knowledge retention and better learning results (Mayer 2001; Tabbers, Martens and Van Merrienboer 2010). In this ODL research, the above was implemented by means of video clips, graphics and links to websites.

\section{Engagement}

The following sub-constructs emerge consistently in the theory on learner engagement.

The implementation of learner engagement deals with general principles on engagement. How can engagement be measured? Many studies have tracked achievement (marks, attendance, etc) but not levels of student engagement in learning (interest, time on task, enjoyment levels) (Taylor and Parsons 2011). Carnahan, Musti-Rao and Bailey (2009) posit that engagement is characterised by behaviours such as involvement in learning tasks and participation in activities. Oud (2009) explains that engagement is a major component of interactivity and can be implemented via practice activities and active participation.

Emotional engagement is related to attitudes (Epstein and McPartland 1976), such as interest or boredom, and is enhanced by individual needs (Fredricks et al. 2004).

Cognitive engagement is relevant to all levels of Bloom's taxonomy (Fredricks et al. 2004; Oud 2009; Shea and Bidjerano 2009). At the basic level of cognitive engagement, learners should gain and recall factual and conceptual knowledge. Engagement helps to transfer information from short-term into long-term memory (Coles 2011). To attain lower levels of Bloom's taxonomy (remembering, understanding and applying), interactive activities should be created that demonstrate concepts, involve learners, or provide opportunities for practising skills (Oud 2009).

At the higher levels of Bloom's taxonomy (analysing, synthesising and evaluating), cognitive engagement involves comprehending complex ideas, mastering difficult skills, investment in learning, self-regulation (Fredricks et al. 2004) and motivational goals (Boekarts, Pintrich and Ziedner 2000). The challenge in ODL is to foster cognitive 
engagement among learners by creating study material that motivates them to devote considerable effort to understanding topics and studying them over a period of time.

\section{Learning activities}

Chi (2009) distinguishes between active, constructive and interactive activities. Preferences and opinions on these were therefore integrated into the surveys. These three sub-constructs are discussed in detail by Oud (2009); Ng'ambi and Johnston (2006) and Taylor and Parsons (2011); and Rhode (2009) respectively.

Active activities involve searching, highlighting, repeating and summarising. Techniques to support learners' focus include bold font, text boxes and animation (if online). The aim is for cognitive processes that activate relevant knowledge, stimulate searches for related information, or encode new information by assimilating it with existing knowledge. This fosters effective learning, since people understand better if they connect something with existing knowledge (Oud 2009). Alternatively, if the information is new, learning is enhanced as knowledge is enriched and existing knowledge strengthened (Chi 2009).

Constructive activities are synonymous with constructivism, which has already been addressed. Going beyond active activities, constructive activities produce additional overt outputs of new content such as ideas that move learners beyond the information provided. This includes explaining concepts to someone, drawing concept maps, taking notes, asking questions, comparing and contrasting, reflecting, linking and justifying. This encourages learners to infer new knowledge (making learning richer) and repair and improve existing knowledge (making it more coherent, accurate and better structured) (Chi 2009). In ODL these self-constructing explorations (Taylor and Parsons 2011) are essential for engagement and critical thinking skills (Ng'ambi and Johnson 2006).

Interactive activities occur through active engagement (Rhode 2009) and use the same cognitive processes as constructive activities (Chi 2009). Interaction involves moving from teacher-directed to learner-centred approaches via overt activities such as learners talking to other people or physically doing something (Chi 2009). It also involves interaction with the educator and peers, which is beyond this article's scope.

Overall, being active is preferable to being passive, being constructive is better than active, and interactivity is better than constructivism (Chi 2009).

\section{Relevance, application, bonding and ownership}

All the sub-constructs in this integrated construct enhance engagement, motivation and interactivity.

Personal relevance increases engagement (Fredricks et al. 2004). Students want application to real-life scenarios rather than pure theory and text (Baniulus et al. 2010). 
Learning should be relevant to students' lives, experiences, culture and interests, enabling them to extend it beyond the learning environment into their wider community and workplace (Taylor and Parsons 2011). Knowledge should link with contextualised problem solving (Grabinger and Dunlap 1995). Although decontextualised skills have broad relevance and are not limited to particular environments, students might not learn how to apply those skills in the workplace. Contextualisation is highly relevant to tourism education, in which learners require real-world vocational training as well as academic foundations.

Applying knowledge to practice has various terms, namely 'resolution' (Shea and Bidjerano 2009), 'learning transfer' (Oud 2009), 'methodical knowledge' (application of subject-specific skills) (Paechter and Maier 2010) and 'authentic learning' (Fredricks et al. 2004). It exercises the highest level of cognitive presence (Fredricks et al. 2004; Shea and Bidjerano 2009) and is a key learning outcome/competency (Paechter and Maier 2010). Achieving knowledge application requires active, meaningful engagement in a realistic context. In ODL, Ambe-Uva (2006) advocates encouraging connectivity via authentic learning. This can be achieved through innovative engagement tools in learning material.

Bonding with and ownership of study material enhances engagement (Fredricks et al. 2004; Taylor and Parsons 2011). Schussler (2009) suggests that engagement goes beyond tangible behaviours and occurs when students develop interest and bond with topics beyond the short term. This is particularly relevant in ODL, in which learning material should achieve this without face-to-face tuition. Both pedagogy (how we teach) and curriculum (what we teach) should engage and absorb learners (Taylor and Parsons 2011). Ideally students are so absorbed that concerns such as time, food, etc. are forgotten (Taylor and Parsons 2011).

\section{RESEARCH METHODOLOGY}

\subsection{Research question}

The title of this article queries whether rich learning environments are what learners really want, despite their merits in theory. This relates to what learners desire in terms of the learning material of the specified module, rather than of a course in its entirety, and is investigated by the research question: How did learners experience the implementation of the four key constructs: course design; engagement; learner activities; and the integrated construct of relevance, application, bonding and ownership?

\subsection{Research design}

In this quantitative empirical study, a cross-sectional survey-based research design was used to obtain data regarding how the four constructs enhanced respondents' 
engagement, motivation and interactivity. The surveys were conducted in two phases, one with a 2011 cohort (traditional study guide) and the other with a 2012 cohort (interactive innovative study guide).

\subsection{Participants}

The population for this study comprised learners in the fourth-year module titled Advanced Tourism Development and Ecotourism. In 2011 the learner population was 51 , of whom 25 responded to the online survey ( $47 \%$ ), while in 2012 the population was 47, of whom 25 responded (53\%), providing identical numbers of participants in each sample. Out of the 50 respondents (across both years), only one was not living in South Africa. The researchers had direct access to these students due to involvement in the module. Table 1 shows the composition of the groups.

Table 1: Characteristics of participants

\begin{tabular}{|l|l|l|l|l|l|}
\hline Item & Category & $\mathbf{2 0 1 1}$ & $\mathbf{2 0 1 2}$ \\
\hline & & Frequency & \% & Frequency & $\%$ \\
\hline \multirow{6}{*}{} & Male & 11 & 44.0 & 17 & 68.0 \\
\cline { 2 - 7 } & Female & 14 & 56.0 & 8 & 32.0 \\
\hline \multirow{6}{|l|}{} \\
\cline { 2 - 7 } & $20-25$ years & 14 & 56.0 & 5 & 20.0 \\
\cline { 2 - 7 } & $26-30$ years & 6 & 24.0 & 6 & 24.0 \\
\cline { 2 - 6 } & $31-35$ years & 4 & 16.0 & 9 & 36.0 \\
\cline { 2 - 7 } & $36-40$ years & 1 & 4.0 & 3 & 12.0 \\
\cline { 2 - 7 } & $41+$ & - & - & 2 & 8.0 \\
\hline
\end{tabular}

\subsection{Measuring instrument}

The questionnaire items were designed by applying key concepts and criteria gleaned from literature. Section A requested biographical information. A five-point Likert scale ranging from 1 (strongly disagree) to 5 (strongly agree) was used for the following sections: section B (course design), section C (engagement), section D (activities) and section $\mathrm{E}$ (relevance, application, bonding and ownership). For some questions, the 2011 students were given the option of 'not applicable'. Table 4 contains the items that emerged as significant under each construct.

\subsection{Procedure and ethics}

Permission for this research was granted in 2011 by the CEMS Research Ethics Committee. Participation was voluntary with individual consent. Data was collected 
via online surveys among the 2011 and 2012 cohorts following the October/November examinations.

\subsection{Data analysis}

The statistical analysis was conducted with SPSS 21 (SPSS Inc. 2012). Descriptive statistics in terms of means, standard deviations, skewness and kurtosis were calculated in order to determine normality. Non-parametric exploratory factor analysis with principle axis factoring (PAF) was conducted and, where necessary, a Promax rotation with Kaiser Normalisation was applied. Due to the small sample $(n<30)$, non-parametric correlational techniques were used to analyse the data. Non-parametric correlations investigate the relationships between the constructs of course design; engagement activities; and relevance, application, bonding and ownership. Depending on the distribution of the data, either the Pearson's R or the Spearman rank-order correlation was used. Results can be considered significant if the p-values are smaller than 0.05 (Salkind 2012). Cross-tabulations were used to determine significant mean differences between the responses of 2011 and 2012, and form the focus of this article.

\subsection{Limitations}

Although the samples were small, there were good response rates: 47 per cent and 53 per cent respectively. The two-cohort approach means that participants in the two studies were not the same groups.

\section{RESULTS AND DISCUSSION}

This research involved 57 questionnaire items in total, of which the 25 that emerged as statistically significant are presented in table 4 and discussed in this article. Results can be considered significant in that a significant difference occurred between the response patterns of 2011 and 2012. The constructs are addressed individually in each of tables 2, 3 and 4. Due to the small sample sizes (both N (2011) and N (2012) = 25), nonparametric correlational analysis was performed.

\subsection{Descriptive statistics}

Table 2 presents summative measures of learners' perceptions of the constructs and indicates whether they are reliable. The original questionnaire had four constructs as discussed earlier. From the factor analysis performed, only two factors emerged, namely 'video clips' and 'study guide' as indicated in table 2. In 2011 and 2012, all the alpha coefficients were higher than the guideline of $\alpha>0.6$ (Nunnally 1978). It therefore appears that, for both phases of the research, the measuring instruments have acceptable 
levels of internal consistency. Since these measures are reliable, the researchers are at liberty to use the findings.

Table 2: Descriptive statistics

\begin{tabular}{|l|l|l|l|l|l|l|l|}
\hline \multicolumn{2}{|l|}{ Construct } & \multicolumn{2}{l|}{ Mean } & \multicolumn{2}{l|}{$\begin{array}{l}\text { Standard } \\
\text { deviation }\end{array}$} & \multicolumn{2}{l|}{$\boldsymbol{\alpha}$} \\
\hline & & 2011 & 2012 & 2011 & 2012 & 2011 & 2012 \\
\hline $1 \mathrm{a}$ & Course design factor 1: Video clips & 3.73 & 4.07 & 0.98 & 0.41 & 0.89 & 0.87 \\
\hline $1 \mathrm{~b}$ & Course design factor 2: Study guide & 4.41 & 3.45 & 0.47 & 0.69 & 0.74 & 0.79 \\
\hline 2 & Engagement & 3.65 & 3.57 & 0.34 & 0.36 & 0.68 & 0.77 \\
\hline 3 & Activities & 3.95 & 3.84 & 0.52 & 0.42 & 0.74 & 0.73 \\
\hline 4 & $\begin{array}{l}\text { Relevance, control, bonding and } \\
\text { critical thinking }\end{array}$ & 4.12 & 3.88 & 0.55 & 0.40 & 0.88 & 0.83 \\
\hline
\end{tabular}

\subsection{Correlations}

Table 3 presents the positive correlations between the constructs in 2011 and 2012. For 2011, engagement is significantly related to course design factor 1a (video clips) and to activities. The integrated construct of relevance, application, bonding and ownership is significantly related to course design factor $1 \mathrm{a}$ (video clips), to factor $1 \mathrm{~b}$ (study guide) and to activities. For 2012, engagement is significantly related to course design factor $1 \mathrm{~b}$ (study guide) and to activities. The relevance, application, bonding and ownership construct is significantly related to course design factor $1 \mathrm{~b}$ (study guide), to engagement and to activities. Significant patterns of agreement occurred in 2011 and 2012 between engagement and activities, as occurred also between factor $1 \mathrm{~b}$ (study guide) and the integrated construct of relevance, control, bonding and critical thinking. The latter implies, for example, that when students appreciated the study guide, they bonded more with the module and grasped its relevance, and vice versa. Similarly, in both years, students who were engaged enjoyed the activities.

Table 3: Non-parametric correlation coefficients for 2011 and 2012

\begin{tabular}{|c|c|c|c|c|c|c|c|c|c|c|}
\hline \multirow[t]{2}{*}{ Construct } & \multicolumn{5}{|l|}{2011} & \multicolumn{5}{|l|}{2012} \\
\hline & CDF1 & CDF2 & Eng & Act & RABO & CDF1 & CDF2 & Eng & Act & RABO \\
\hline $\begin{array}{l}\text { 1a. Course } \\
\text { design factor } \\
\text { 1: Video clips } \\
\text { (CDF1) }\end{array}$ & 1.00 & - & & & & 1.00 & - & & & \\
\hline $\begin{array}{l}\text { 1b. Course } \\
\text { design factor } \\
\text { 2: Study guide } \\
\text { (CDF2) }\end{array}$ & -0.33 & 1.00 & - & & & 0.08 & 1.00 & - & & \\
\hline
\end{tabular}




\begin{tabular}{|c|c|c|c|c|c|c|c|c|c|c|}
\hline \multirow[t]{2}{*}{ Construct } & \multicolumn{5}{|l|}{2011} & \multicolumn{5}{|l|}{2012} \\
\hline & CDF1 & CDF2 & Eng & Act & RABO & CDF1 & CDF2 & Eng & Act & RABO \\
\hline $\begin{array}{l}2 . \\
\text { Engagement } \\
\text { (Eng) }\end{array}$ & $0.43^{*}$ & 0.21 & 1.00 & - & & 0.21 & $0.48^{*}$ & 1.00 & - & \\
\hline $\begin{array}{l}\text { 3. Activities } \\
\text { (Act) }\end{array}$ & 0.22 & 0.13 & $0.57^{* *}$ & 1.00 & - & -0.06 & 0.23 & $0.66^{* *}$ & 1.00 & - \\
\hline $\begin{array}{l}\text { 4. Relevance, } \\
\text { application, } \\
\text { bonding and } \\
\text { ownership } \\
\text { (RABO) }\end{array}$ & $-0.41^{*}$ & $0.56^{\star *}$ & 0.10 & $0.40^{*}$ & 1.00 & 0.36 & $0.64^{* *}$ & $0.69^{* *}$ & $0.48^{*}$ & 1.00 \\
\hline
\end{tabular}

\subsection{Cross-tabulations}

The cross-tabulations in table 4 portray the distribution of response patterns of 2011 and 2012 and indicate the significance levels for differences between responses of the two years. The table is structured under the four key constructs as headers, and the discussion of each construct follows after the table and forms the focus of this article. The cross-tabulations enable comparisons between 2011 students using traditional study material and 2012 students using the new engaging material. Under each construct, a selection of responses that emerged as significant are discussed, using a Pearson or Spearman correlation ( $p$-value $<0.05$ ). Due to the small sample, responses that emerged as significant, with $\mathrm{p}<0.10$, are also reported. In all the cases in table 4 , there was a significant difference between the results of 2011 and 2012. Questions to which responses were not significant are excluded from table 4.

\section{Course design (CD)}

When students rated the item CD4, 'I liked the format and approach of the study guide', the frequency of 'agree' ratings was higher in 2012 (20) than in 2011 (16), i.e. $\left(2011: f_{\mathrm{i}=} 16 ; 2012: f_{\mathrm{i}=} 20\right)$, but the frequency of 'strongly agree' was higher in 2011 (9) than in 2012 (2), i.e. (2011: $f_{\mathrm{i}=}$ 9; 2012: $\left.f_{\mathrm{i}=} 2\right)$. When 'agree' and 'strongly agree' are combined, the frequencies are 25 for 2011 and 22 for 2012. This surprisingly indicates a stronger liking for the traditional material. Similar response patterns emerged for CD7 on 'understanding', with 'agree' $\left(2011: f_{\mathrm{i}=} 11 ; 2012: f_{\mathrm{i}=} 19\right)$ and 'strongly agree' (2011: $f_{\mathrm{i}=} 12 ; 2012: f_{\mathrm{i}=}$ ). Cumulatively these suggest that the simpler 2011 material might aid understanding more than the richer 2012 material. For CD9, 'The study guide is well structured', ratings followed a similar pattern, indicating a significant difference between the years. To consolidate this section, responses to CD4, CD7 and CD9 result in similar patterns, with the majority of 2012 participants (frequencies of 20, 19 and 20, respectively) selecting 'agree'. It appears they experienced the new 


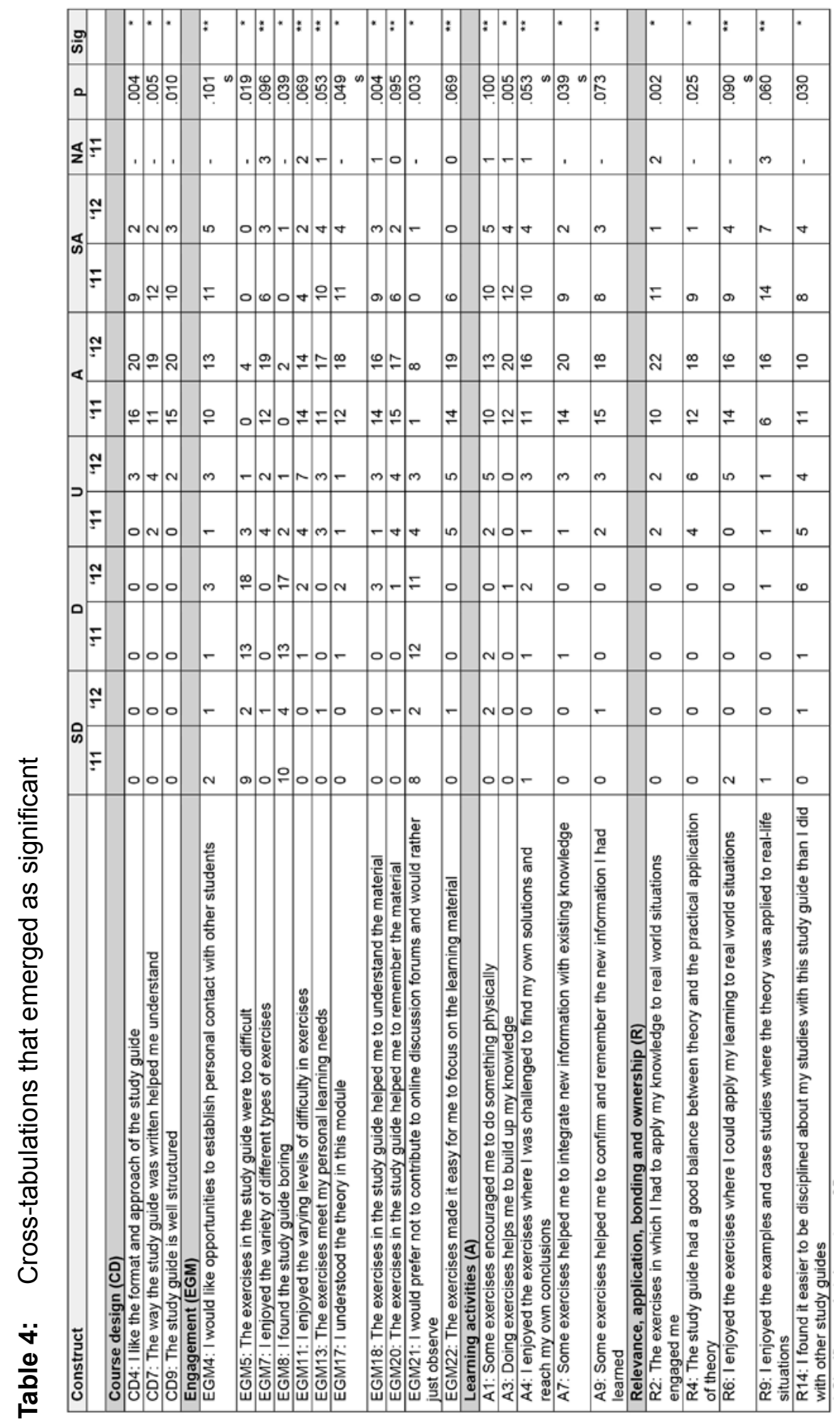


course material positively in terms of liking the structure, format and approach, and it aiding understanding. However, a relatively high number of 2011 participants rating the traditional material selected 'strong agreement' (frequencies of 9, 12 and 10 respectively) for these criteria in contrast to 2012 frequencies of 2, 2 and 3 respectively.

Due to the 2012 students having the richer study material, the 2012 cohort were asked additional questions (not in table 4) to ascertain opinions on learner engagement tools in this guide (figure 1) to determine whether they aided learning and engagement. Students were positive about the exercises. The item, 'The instructions for the exercises were clear' obtained a frequency of 18 for 'agree'. For 'The exercises were too difficult', a frequency of 20 for 'disagree' indicated the difficulty level was appropriate. 'The exercises that provided feedback helped me to engage more with this module' revealed a frequency of 16 in agreement, suggesting appreciation of feedback. When rating 'The different components (newsflash, questions, video clips, etc.) in this study guide overwhelmed me', results were distributed evenly over 'disagree', 'unsure' and 'agree' with frequencies of 7, 7 and 8 respectively. However, when rating 'The different components (newsflash, questions, video clips, etc.) in this study guide helped me engage with this module', 17 agreed. Thus 17 out of 25 agreed that these tools aid engagement, yet a third of the cohort found the activities overwhelming, which could indicate an environment that is too demanding.

\section{Engagement (EGM)}

The exercises were designed with practice, participation, interest, enjoyment, time spent and interaction in mind. In designing the questionnaire, items were grouped under sub-constructs of implementation of engagement, cognitive engagement and emotional engagement.

In the testing of implementation of engagement, certain statements related to learner engagement tools in the form of exercises. In responding to EGM7 on the '... variety of different types of exercises', the 2012 learners scored their material higher than the 2011 learners (2011: $f_{\mathrm{i}}=12$; 2012: $\left.f_{\mathrm{i}}=19\right)$ for 'agree', while for 'strongly agree', only a quarter of 2011 learners scored their material highly $\left(2011: f_{\mathrm{i}}=6\right.$; 2012: $\left.f_{\mathrm{i}}=3\right)$. These results overall showed a higher level of enjoyment by 2012 students, suggesting that they appreciated the variety. However, test responses to the item EGM11 on '... varying levels of difficulty in exercises' are distributed across the spectrum from 'disagree' to 'strongly agree'. Some were 'unsure' (2011: $\left.f_{\mathrm{i}}=4 ; 2012: f_{\mathrm{i}}=7\right)$. This could suggest that while 2012 students enjoyed the different exercises, a tension existed due to the richness of incorporating varying levels of difficulty.

Regarding emotional engagement, EGM8: 'I found the study guide boring' revealed that in both years the majority did not find it boring, with 'strongly disagree' (2011: $\mathrm{f}_{\mathrm{i}}=10$; 2012: $\left.\mathrm{f}_{\mathrm{i}}=4\right)$ and 'disagree' (2011: $\mathrm{f}_{\mathrm{i}}=13$; 2012: $\left.\mathrm{f}_{\mathrm{i}}=17\right)$. The 2012 material scores highly in the 'disagree' scale, but less highly than 2011 material in the 'strongly 
disagree' scale. Regarding EGM13 on exercises meeting '... personal learning needs', the same pattern emerged with 'agree' (2011: $\mathrm{f}_{\mathrm{i}}=11 ; 2012$ : $\left.\mathrm{f}_{\mathrm{i}}=17\right)$ and 'strongly agree' (2011: $\mathrm{f}_{\mathrm{i}}=10 ; 2012: \mathrm{f}_{\mathrm{i}}=4$ ). The high level of agreement in 2012 is satisfying to the course designers, but one would have expected higher frequencies for 'strongly agree'.

In testing cognitive engagement, three items relate to lower levels of Bloom's taxonomy (Bloom 1956) in an ODL context, namely understanding and remembering. For EGM18: '.. understand the material', 2011 students with simple uniform-style exercises rated these fairly highly with more 'strongly agrees' than 2012 students with a range of interactive exercises at varying levels. 'Agree' returned (2011: $f_{\mathrm{i}}=14$; 2012: $\left.f_{\mathrm{i}}=16\right)$ and 'strongly agree' $\left(2011: f_{\mathrm{i}}=9 ; 2012: f_{\mathrm{i}}=3\right)$. In the rating of EGM17: 'I understood the theory ...', the same tendency emerged. For EGM20 on recall ('exercises ... helped me remember the material'), responses for 'agree' were (2011: $\mathrm{f}_{\mathrm{i}}=15 ; 2012$ : $\left.\mathrm{f}_{\mathrm{i}}=17\right)$ and for 'strongly agree' (2011: $\left.\mathrm{f}_{\mathrm{i}}=6 ; 2012: \mathrm{f}_{\mathrm{i}}=2\right)$. Finally, consider EGM22: 'The exercises made it easy for me to focus on the learning material'. Responses for 'agree' were (2011: $\left.\mathrm{f}_{\mathrm{i}}=14 ; 2012: \mathrm{f}_{\mathrm{i}}=19\right)$ and for 'strongly agree' (2011: $\mathrm{f}_{\mathrm{i}}=6$; 2012: $\mathrm{f}_{\mathrm{i}}=0$ ), again demonstrating a strong clustering of 2012 students selecting 'agree' more than 2011 students. This indicates support for the new ODL material yet raises concerns since 2011 students more consistently selected 'strongly agree'. Items that relate to higher levels of Bloom's taxonomy are A3, A4, A7, R2, R6 and R9, which are addressed later.

\section{Activities}

Table 4 shows that the pattern identified above continues in the activities construct. Using Chi's (2009) categories of active, constructive and interactive activities, new activities were designed for the 2012 material. Two questions addressed active activities for retaining new knowledge and focusing the learner's gaze by actively doing something. A1: 'Some exercises encouraged me to do something physically such as underlining, paraphrasing, jotting things down, etc.', and A9: '... helped me confirm and remember the new information I had learned'. In both, when the 'agree' and 'strongly agree' categories are combined, 2011 students were slightly more positive than 2012 students, although the 2012 cohort had more learner engagement tools.

In testing the constructive activities, A3: 'Doing exercises helps me to build up my knowledge' has a p-value of .005, pinpointing significant differences due to 'agree' (2011: $\left.\mathrm{f}_{\mathrm{i}}=12 ; 2012: \mathrm{f}_{\mathrm{i}}=20\right)$ and 'strongly agree' (2011: $\left.\mathrm{f}_{\mathrm{i}}=12 ; 2012: \mathrm{f}_{\mathrm{i}}=4\right)$. Similar response patterns emerged for the other statements relating to constructive activities, namely A4: 'I enjoyed the exercises where I was challenged to find my own solutions and reach my own conclusions' and A7: 'Some exercises helped me integrate new information with existing knowledge'. The two bar graphs in figure 3 portray the prevailing response pattern, with figure 3.1 representing A7. With regard to the higher levels of Bloom's taxonomy and in line with Oud (2009) and Chi (2009), A4 represents the analysis level, and $\mathrm{A} 3$ and $\mathrm{A} 7$ the synthesis level. 


\section{Relevance, application, bonding and ownership}

In this section, R2, R6 and R9 test the higher levels of Bloom's taxonomy in line with the work of Shea and Bidjerano (2009) and Taylor and Parsons (2011). Engagement is enhanced when ODL material is personally relevant to learners, can be applied to realworld situations, and involves contextualised problem solving. The 2012 study material had several exercises designed to this end. R2 related to '.. applying knowledge to realworld situations' while R6 investigated '... applying my learning to real-world situations' (figure 3.2). These results were similar but R2's $\mathrm{p}=.002$ showed a very significant difference due to 'agree' (2011: $\left.f_{\mathrm{i}}=10 ; 2012: f_{\mathrm{i}}=22\right)$ and 'strongly agree' $\left(2011: f_{\mathrm{i}}=11\right.$; 2012: $\left.f_{\mathrm{i}}=1\right)$. In this case, combining 'agree' and 'strongly agree' showed that the 2012 students (23) were more positive than the 2011 students (21).

$\mathrm{R} 9$ related not to activities but to examples and case studies where the theory was applied to real-life situations, with 'agree' (2011: $\left.f_{\mathrm{i}}=6 ; 2012: f_{\mathrm{i}}=16\right)$ and 'strongly agree' (2011: $f_{\mathrm{i}}=14 ; 2012: f_{\mathrm{i}}=7$ ). This indicates higher combined agreement from the 2012 students (figure 3.2). The 2012 cohort seemed to prefer it when the application of theory to real-world contexts via examples and case studies was given to them (R9), rather than when they themselves had to apply it (R2 and R6).

The prevailing pattern is seen regarding contextualised problem solving in R4: ' ... good balance between theory and practical application of theory'. The 2012 students, with all the engagement tools (figure 1) were less positive than the 2011 students with a simpler learning context (more theory and less application).

Although the 2012 results are not as positive as expected, there is evidence of both learner engagement and enjoyment being achieved. If 'agree' and 'strongly agree' are collapsed for the items R2, R6 and R9, frequencies of 23, 20 and 23 emerge respectively out of the sample of 25 .

Finally, in assessing bonding with and ownership of the module (R14: 'I found it easier to be disciplined about my studies with this study guide ...'), the result is notable and deviates from the prevailing pattern. With 2011's traditional familiar study guide, 11 agreed and 8 strongly agreed; while for 2012's rich and stimulating study guide, 10 agreed and 4 strongly agreed. This is portrayed in figure 4 .

In summary, with the exception of two questions, there were higher frequencies of 'agree' for the 2012 study guide and 'strongly agree' for the 2011 study guide (see figure 3 ). Although the 2012 results are not negative, they are less positive than anticipated, suggesting that the material may be too rich. The 2011 learners were comfortable with traditional and predictable study material. Demographic composition in terms of age and gender (Table 1) might also have influenced results. It is a limitation that the researchers do not know more about each cohort. 


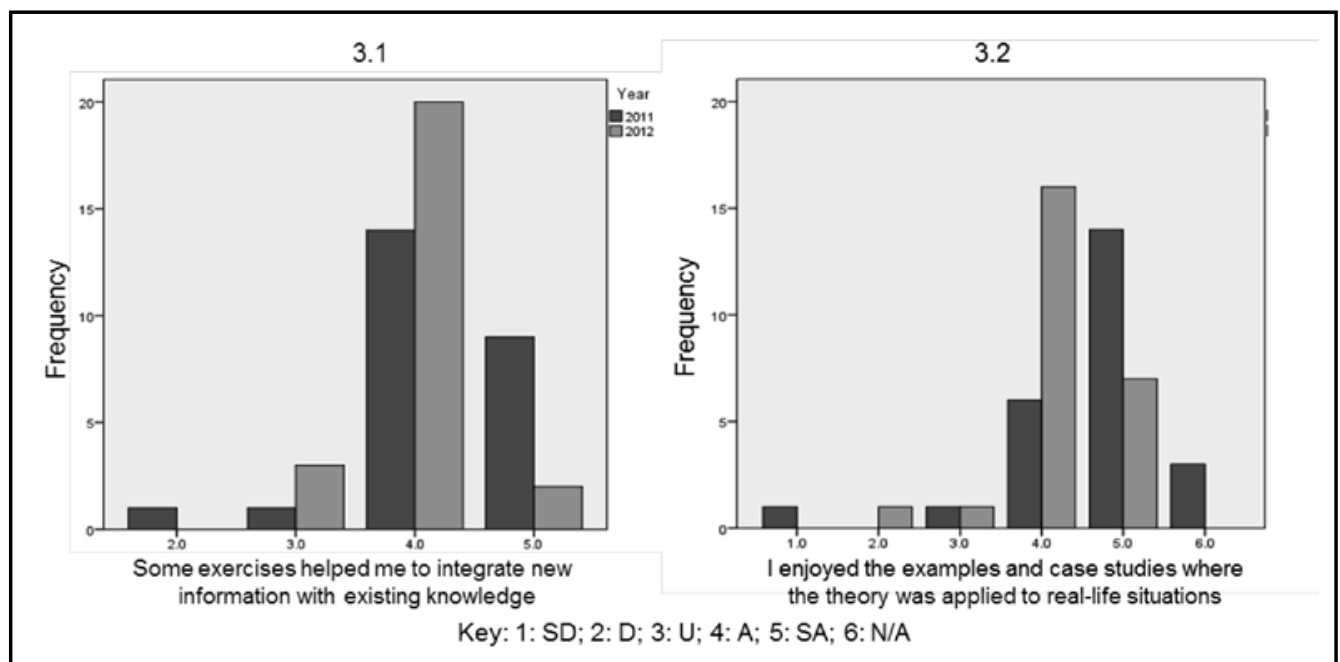

Figure 3.1: Prevailing response pattern

Figure 3.2: Prevailing response pattern

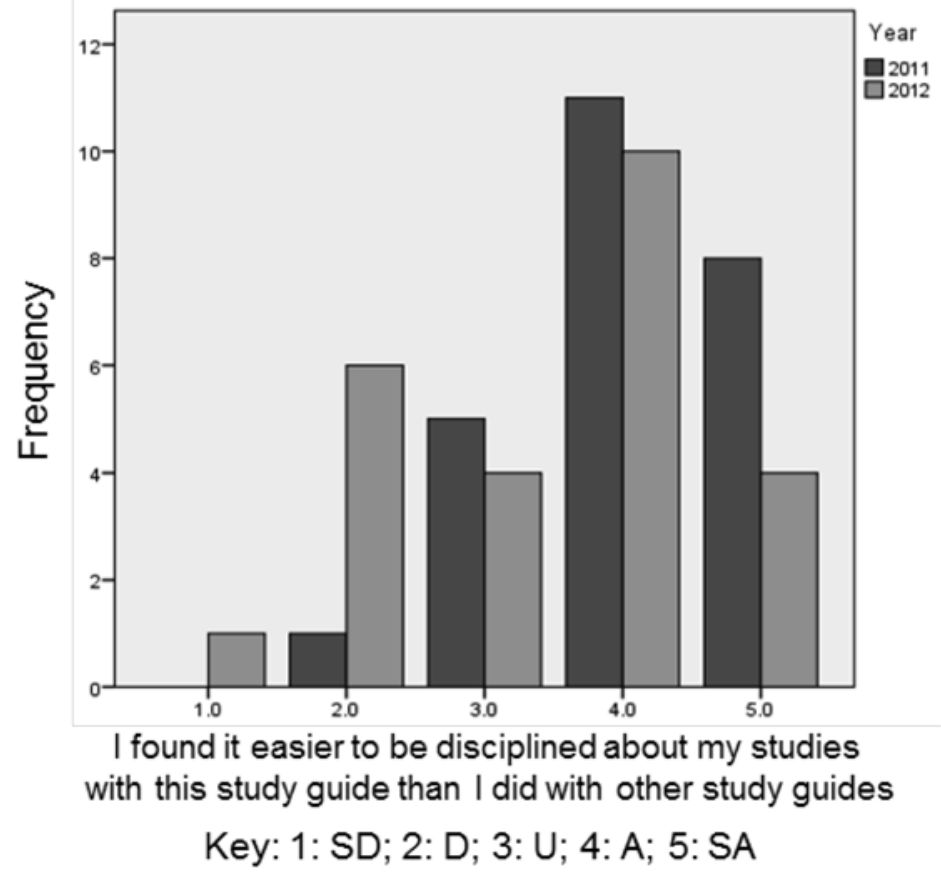

Figure 4: An interesting response pattern 


\section{CONCLUSION AND RECOMMENDATIONS}

Using study materials to offer learner-engagement tools in rich environments (REALs) calls for creativity and innovation. It also requires reflection on learning theory to inform the design of ODL materials for optimal impact (Louw 2010). The literature review presented learning theory constructs that influenced the new study guide and informed the evaluation criteria. In this section, the authors summarise the implementation of these constructs in the new study material and briefly review the main findings of the investigation into students' perceptions.

With regard to implementation of learning theory, the new study guide aimed, as far as possible in an ODL context, to offer a constructivist approach. Learner engagement tools were designed to support guided discovery; learner reflection; ownership of learning and activities; exposure to authentic tasks; exploration beyond the material provided; repairing existing knowledge and actively constructing knowledge; and fostering motivation and investment in learning.

This was done via activities promoting self-application of theory to learners' personal and work life; active recording of thoughts; describing concepts to others; roleplay as consultants explaining appropriate theory to clients; and stating own opinions, then adapting them as further theory is added (i.e. building on an activity while moving through a learning unit). Newspaper and video clips were used to demonstrate theory in real-world contexts, and learners were referred to websites for active engagement, for example using currency convertors, exploring zoning maps, or doing quizzes. Reflection boxes asked learners to 'think', 'compare', 'play with scenarios', 'note differences', 'consider challenges', 'provide own views', etc.

With regard to students' perceptions, Louw (2010) proposes that students should have a say in new study material. This research therefore investigated their opinions (via a research instrument informed by theory) on the innovative ODL study guide (developed using learning theory).

The research question posed in section 4: How did learners experience the implementation of the four key constructs: course design; engagement; learner activities; and the integrated construct of relevance, application, bonding and ownership? has been rigorously addressed in section 5 . For all four constructs, similar patterns emerged, with the positive levels of 'agree' amongst 2012 learners suggesting that this REAL does enhance engagement, motivation and learner-centred interactivity, which in turn improves learning. However, not all aspects of the new approach were as well received as anticipated. Low levels of 'strong agreement' amongst the 2012 cohort combined with the 2011 learners being clearly comfortable with the familiarity, predictability and ease of use of their study material suggest that this REAL may be too rich and learners are not necessarily learning better via this route.

Although the sample is too small to confidently generalise the findings to the wider institution, this exploratory research has made a dual contribution - firstly in terms of 
developing a new research instrument based on theory, and secondly in terms of the results. The research is interesting in light of the greater debate at Unisa. This initiative developed with and approved by the DCLD, yielded unexpected findings, leading the researchers to ask whether this innovative approach, in line with what educators are being encouraged to do, is really what learners want?

The findings suggest that educators should discerningly regulate the richness and depth of learning material when aiming to enhance engagement, motivation and interactivity in the ODL context in South Africa. Overload of isolated learners should be avoided, taking cognisance of the fact that they study outside conventional classbased situations, with lives impacted by factors such as employment and family responsibilities. Alternatively, students may adapt to the new approach as such learning activities become increasingly familiar. However, this raises the question whether such REALs should be gradually introduced to students. It also raises a concern that, as this module goes online in 2015, the increased richness of this environment may add further complexities.

Future research should be undertaken to determine whether such results re-occur and to probe further via in-depth exploratory interviews with a sample of learners. Comparisons between the cohorts of 2012, 2013 and 2014 (innovative hard-copy study guide) and 2015 (innovative online material) should also provide insights. Moreover, similar research could be undertaken on other modules at different levels.

\section{NOTE}

1. The terms 'student' and 'learner' are used interchangeably in this article.

\section{REFERENCES}

Alessi, S. M. and S. R. Trollip. 2001. Multimedia for learning. Boston: Allyn and Bacon.

Ambe-Uva, T. N. 2006. Interactivity in distance education: The National Open University of Nigeria (NOUN) experience. Turkish Online Journal of Distance Education 7(4): 101-109.

Baniulus, K., V. Kersiene, V. Petreikiene and A. Slotkiene. 2010. A case study: Impact of the interactivity level to e-learning outcomes. Paper presented at the $16^{\text {th }}$ International Conference on Information and Software Technologies IT 2010. Available at http://isd.ktu.lt/it2010//material/ Research/5_ITTL_1.pdf (accessed 18 September 2011).

Bloom, B. S. 1956. Taxonomy of educational objectives. Handbook I: The cognitive domain. New York: David McKay.

Boekarts, M., P. R. Pintrich and M. Ziedner. (Ed.). 2000. Handbook of self-regulation: Theory, research and applications. San Diego, CA: Academic Press.

Carlson, S. 2005. The net generation goes to college. The Chronicle of Higher Education 7 October 2005. Available at http://chronicle.com/article/The-Net-Generation-Goes-to/12307 (accessed 27 June 2013). 
Carnahan, C., S. Musti-Rao and J. Bailey. 2009. Promoting active engagement in small group learning experiences for students with autism and significant learning needs. Education and Treatment of Children 32(1): 37-61.

Chi, M. T. H. 2009. Active-constructive-interactive: A conceptual framework for differentiating learning activities. Topics in Cognitive Science 1: 73-105.

Coles, C. 2011. The use of wikis and online classrooms to promote deeper learning. Paper presented at the International Conference on E-Learning in the Workplace 2011. Available at http://www. icelw.org/program/ICELW\%202011\%20Proceedings/Papers/Coles.pdf (accessed 6 September 2013).

Dobrovolny, J. 2006. How adults learn from self-paced, technology-based corporate training: New focus for learners, new focus for designers. Distance Education 27(2): 155-170.

Epstein, J. L. and J. M. McPartland. 1976. The concept and measurement of the quality of school life. American Educational Research Journal 13: 15-30.

Fredricks, J. A., P. C. Blumenfeld and A. H. Paris. 2004. School engagement: Potential of the concept, state of the evidence. Review of Educational Research 74(1): 59-110.

Glenn, J. M. 2000. Teaching the Net Generation. Business Education Forum 54(3): 6-14.

Grabinger, R. S. and J. C. Dunlap. 1995. Rich environments for active learning: A definition. Association for Learning Technology Journal 3(2): 5-34.

Hsi, S. and E. Soloway. 1998. Learner-centered design: Addressing, finally, the unique needs of learners. Paper presented at the CHI 98 conference 18-23 April.

Louw, W. 2010. Africanisation: A rich environment for active learning on a global platform. Progressio 32(1): 42-54.

Mayer, R. E. 2001. Multimedia learning. New York: Cambridge University Press.

Moley, P. F., P. E. Bandré and J. E. George. 2011. Moving beyond readability: Considering choice, motivation and learner engagement. Theory into Practice 50(3): 247-253.

Ng'ambi, D. and K. Johnston. 2006. An ICT-mediated constructivist approach for increasing academic support and teaching critical thinking skills. Educational Technology \& Society 9(3): 244-253.

Nunnally, J. 1978. Psychometric theory. New York: McGraw Hill.

Oud, J. 2009. Guidelines for effective online instruction using multimedia screencasts. Reference Services Review 37(2): 164-177.

Paechter, M. and B. Maier. 2010. Online or face-to-face? Students' experiences and preferences in e-learning. Internet and Higher Education 13: 292-297.

Rhode, J. F. 2009. Interaction equivalency in self-paced online learning environments: An exploration of learner preferences. International Review of Research in Open and Distance Learning 10(1): $2-23$.

Salkind, N. J. 2012. Exploring research. 2nd ed. Salt River, NJ: Pearson.

Schussler, D. L. 2009. Beyond content: How teachers manage classrooms to facilitate intellectual engagement for disengaged students. Theory into Practice 48: 114-121.

Shea, P. and T. Bidjerano. 2009. Cognitive presence and online learner engagement: A cluster analysis of the community of enquiry framework. Journal of Computing in Higher Education 21: 199217.

SPSS Inc. 2012. SPSS 20.0 for Windows. Chicago, IL: Author. 
Tabbers, H. K., R. L. Martens and J. J. G. van Merriënboer. 2010. Multimedia instructions and cognitive load theory: Effects of modality and cueing. British Journal of Educational Psychology 74(1): 71-81.

Taylor, L. and J. Parsons. 2011. Improving student engagement. Current Issues in Education 14(1). Available at http://cie.asu.edu/ (accessed 20 September 2011).

Willms, J. D. 2003. Student engagement at school: A sense of belonging and participation. Paris: Organization for Economic Cooperation and Development (OECD). 